\title{
ANALISIS FAKTOR GAYA KEPEMIMPINAN, LINGKUNGAN KERJA, DAN KONFLIK TERHADAP TURNOVER KARYAWAN BAGIAN SEWING PT. SOLO KAWISTARA GARMINDO
}

\author{
Tiyas Dwi Hapsari, Istiqomah, Ratna Damayanti \\ Fakultas Ekonomi Program Studi Manajemen Universitas Islam Batik Surakarta \\ E-mail : tiyasdwihapsari@gmail.com
}

\begin{abstract}
This research goals to know and explain the effectaccording to the simultaneous and partial method inLeadership Style $\left(X_{1}\right)$, Fieldwork $\left(X_{2}\right)$, and Conflict $\left(X_{3}\right)$ Towards Turnover Employees in Sewing Section in PT. Solo Kawistara Garmindo. The population in this research is 300 respondents taken from the permanent employees in sewing section. The samples of this research are 75 employees. Sampling technique uses the nonprobability sampling method. The kind of this research is a descriptive quantitative research. The method of collecting data is using questionnaires. The technique of data analysis uses multiple linear regressions. The result of the research shows that F-test of leadership style, fieldwork, and conflict simultaneously and significantly affect the turnover. The result of T-test shows that the leadership style partially does not affect toward the turnover, on the other hand, fieldwork and conflict partially affect toward the turnover. The model of multiple linear regressions in this research is $Y=10,972-0,392 X_{1}+$ $0,286 X_{2}+0,759 X_{3}$. Tended to thenext researchers, they should add another variables that can affect the level of turnover employees, because by the decline in turnover rates, it will affect the company, because the leadership style variables that examined in this research indicate no influence, so it is expected for the company leaders in PT. KawistaraGarmindo to improve the selfquality of the current leadership and expected in the future, to bemore improved in the effort in improving the performance so that it can be more productive and reduces the turnover employees.
\end{abstract}

Keywords : Leadership Style, Fieldwork, Conflict, Turnover

\section{PENDAhUluan}

Pada era globalisasi saat ini, institusi atau organisasi bisnis bersaing untuk menguasai target market. Berbagai inovasi dilakukan perusahaan agar dapat stabil bertahan di keadaan bisnis. Apabila perubahan situasi tidak dapat diantisipasi akan berdampak di dalam perusahaan. Oleh sebab itu perusahaan harus bisa melewati dan memprediksi perubahan situasi lingkungan bisnis dan harus cepat tanggap, akurat, cermat, dan jelas serta tepat. Perkembangan usaha sangat tergantung pada hasil kerja pegawai di setiap perusahaan.

Asset yang paling berharga dimiliki perusahaan ialah sumber daya manusia, merupakan salah satu poros dalam melakukan langkah, menentukan misi serta mampu mengambil keputusan yang akurat demi menuju sasarang yang diinginkan perusahaan atau organisasi.

Faktor yang mempengaruhi tingkat turnover yang pertama adalah gaya kepemimpinan. Seorang pemimpin merupakan salah satu faktor yang dapat mempengaruhi berhasil tidaknya suatu 
organisasi atau perusahaan yang dikelola. Suatu perusahaan diharuskan mempunyai seorang pemimpi yang handal dalam mengelola sumber daya manusia, sebagai atasan harus mampu mengantisipasi masa depan perusahaan dan mengambil peluang perusahaan yang ada serta dapat menyelesaikan permasalahan yang terjadi diorganisasi sehingga mencapai tujuan yang diharapkan.

Faktor yang kedua lingkungan kerja PT. Solo Kawistra Garmindo yang penulis teliti yaitu fisik dan non fisik. Lingkungan non fisik di perusahan memang belum begitu baik. namun demikian, untuk lingkungan fisik masih terdapat beberapa fasilitas maupun kondisi ruagan yang belum layak mendukung, seperti suhu udara penggap dan panas, serta ruangan kerja yang kurang luas ditakutkan berdampak buruk sehingga menyebabkan karyawan tidah betah bekerja.

Faktor ketiga yang mempengaruhi turnover adalah konflik. Konflik diakibatkan dari perbedaan ciri yang dibawa setiap individu. Perbedaan yang terjadi meliputi ciri fisik, antara lain kemampuan, keyakinan, dan adat istiadat. Konflik keadaan yang wajar dalam masyarakat antara masyarakat satu dengan yang lainnya.

\section{KAJIAN PUSTAKA}

a) Menurut Issa, et al (2013: 256) berpendapat turnover intention ialah keinginan untuk meninggalkan pekerjan secara sukarela, atau tidak sukarela dapat merugikan perusahaan dan dapat juga mempengaruhi hasil kerja karyawan. Indikator yang mempengaruhi tingkat turnover :

- Berhenti bekerja

- Meninggalkan pekerjaan

- Mencari pekerjaan lain

b) Pengertian gaya kepemimpinan menurut Hasibuan (2011: 157), gaya kepemimpinan ialah suatu sikap atau cara seorang pemimpin untuk dapat mempengaruhi karyawan agar dapat bekerja secara tim atau kelompok dan produktif untuk mencapai sasaran perusahaan. Indikator yang dapat mempengaruhi gaya kepemimpinan :

- Wewenang dalam mengambil keputusan

- Keahlian memotivasi pegawai

- Kemampuan dalam berkomunikasi

- Mengendalikan pegawai

- Komitmen

- Dapat mengendalikan emosional

c) Pengertian lingkungan kerja meliputi kerja fisik dan non fisik menurut Sedamayanti, (2011: 26) lingkungan kerja fisik ialah suatu kondisi yang berada di sekitar tempat kerja yang meliputi penerangan, berbagai macam warna ruang kerja, pergantian udara, serta suara musik dapat mempengaruhi diri dalam menyelesaiakan tugas yang diberikan. Sedangkan lingkungan kerja non fisik adalah hubungan sosial ditempat kerja baik hubungan secara vertikal maupun horisontal. Indikator lingkungan kerja fisik dan non fisik menurut Sedamayanti meliputi :

- Situasi tempat kerja

- Hubungan dengan pegawai lain

- Akomodasi yang tersedia

- Penerangan kondisi kerja

- Pergantian udara

- Kebisingan area kerja 
- Keamanan kawasan kerja

d) Menurut Wirawan (201: 1) berpendapat konflik adalah suatu kondisi adanya perbedaan akan selalu ada karena setiap karyawan memiliki keinginan, tujuan, dan pengetahuan yang beragam. Perbedaan pada manusia misalnya jenis kelamin, perekonomian, status sosial, keyakinan, suku bangsa, budaya, dan adat istiadat menjadi penyebab timbulnya konflik. Indikator konflik sebagai berikut :

- Perbedaan tujuan dan kepentingan

- Perbedaan pemahaman

- Perbadaan cara pandang

- Perbedaan kepribadian

\section{METODOLOGI}

Jenis penelitian deskriptif kuantitatif. Lokasi peneelitian PT. Solo Kawistara Garmindo. Waktu penelitian selama bulan Juli 2019 sampai Januari 2020. Populasi penelitian 300 responen dan sampel yang diambil 75 karyawan bagian sewing. Menggunakan teknik non probability sampling dan alat uji menggunakan analisis regresi linier berganda.

\section{HASIL DAN PEMBAHASAN}

Analisis Data

a. Deksriptif Responden

1) Jenis Kelamin

\begin{tabular}{cccc}
\hline No & Jenis Kelamin & Jumlah & Persentase \\
\hline 1. & Pria & 25 & $33 \%$ \\
2. & Wanita & 30 & $77 \%$ \\
\hline & Jumlah & 75 & $100 \%$ \\
\hline
\end{tabular}

Jenis kelamin yang paling dominan yaitu wanita sebanyak $77 \%$ atau 30 orang dan pria sebanyak $33 \%$ atau 25 orang.

2) Umur

\begin{tabular}{cccc}
\hline No & Kelompok Umur & Jumlah & Persentase \\
\hline 1. & 20-25 tahun & 68 & $91 \%$ \\
2. & 26-31 tahun & 3 & $4 \%$ \\
3. & $>32$ tahun & 4 & $5 \%$ \\
\hline & Jumlah & 75 & $100 \%$ \\
\hline
\end{tabular}


Umur responden yang paling banyak adalah 20 hingga 25 tahun sebesar $91 \%$ atau 68 orang. Karena diusia tersebut masih memiliki semangat tinggi dalam bekerja dan termasuk usia produktif.

a) Tingkat Pendidikan

\begin{tabular}{cccc}
\hline No & Tingkat Pendidikan & Jumlah & Persentase \\
\hline 1. & SD & 3 & $45 \%$ \\
2. & SMP & 4 & $5 \%$ \\
3. & SMK/SMK & 68 & $91 \%$ \\
\hline & Jumlah & 75 & $100 \%$ \\
\hline
\end{tabular}

Karakteristik reponden tingkat pendidikan yang paling dominan lulusan SMA/SMK, karena berpendidikan SAM/SMK sudah berumur maka memiliki atau pengalaman yang bagus.

b) Masa Kerja

\begin{tabular}{cccc}
\hline No & Masa Kerja & Jumlah & Persentase \\
\hline 1. & $<3$ tahun & 51 & $68 \%$ \\
2. & $3-9$ tahun & 19 & $25 \%$ \\
3. & $10-16$ tahun & 2 & $3 \%$ \\
4. & $>17$ tahun & 3 & $4 \%$ \\
\hline Jumlah & & 75 & $100 \%$ \\
\hline
\end{tabular}

Masa kerja kurang dari 3 tahun yang paling berdominan dari klarifikasi yang lain yaitu sebesar $68 \%$ atau 51orang.

b. Analisis Data

a) Uji Instrumen

1. Uji Validitas

\begin{tabular}{|c|c|c|c|}
\hline Pertanyaa & $\mathrm{r}_{\text {hitung }}$ & $\mathrm{r}_{\text {tabel }}$ & Keterangan \\
\hline \multicolumn{4}{|c|}{ Turnover Karyawan } \\
\hline TK_1 & 0,350 & 0.188 & Valid \\
TK_2 & 0,681 & 0.188 & Valid \\
TK_3 & 0,618 & 0.188 & Valid \\
TK_4 & 0,675 & 0.188 & Valid \\
TK_5 & 0,816 & 0.188 & Valid \\
TK_6 & 0,688 & 0.188 & Valid \\
TK_7 & 0,550 & 0.188 & Valid \\
\hline \multicolumn{4}{|c|}{ Gaya Kepemimpinan } \\
\hline \multicolumn{4}{|c}{} \\
\hline
\end{tabular}




\begin{tabular}{|l|l|l|l|}
\hline GK_1 & 0,680 & 0.188 & Valid \\
GK_2 & 0,631 & 0.188 & Valid \\
GK_3 & 0,657 & 0.188 & Valid \\
GK_4 & 0,653 & 0.188 & Valid \\
GK_5 & 0,713 & 0.188 & Valid \\
GK_6 & 0,557 & 0.188 & Valid \\
GK_7 & 0,590 & 0.188 & Valid \\
GK_8 & 0,778 & 0.188 & Valid \\
\hline \multicolumn{4}{|c|}{ Lingkungan Kerja } \\
\hline LK_1 & 0,381 & 0.188 & Valid \\
LK_2 & 0,296 & 0.188 & Valid \\
LK_3 & 0,571 & 0.188 & Valid \\
LK_4 & 0,779 & 0.188 & Valid \\
LK_5 & 0,703 & 0.188 & Valid \\
LK_6 & 0,409 & 0.188 & Valid \\
LK_7 & 0,687 & 0.188 & Valid \\
LK_8 & 0,693 & 0.188 & Valid \\
LK_9 & 0,759 & 0.188 & Valid \\
LK_10 & 0,297 & 0.188 & Valid \\
\hline \multicolumn{5}{|c|}{ Konflik Kerja } \\
\hline KK_1 & 0,763 & 0.188 & Valid \\
KK_2 & 0,861 & 0.188 & Valid \\
KK_3 & 0,705 & 0.188 & Valid \\
KK_4 & 0,848 & 0.188 & Valid \\
KK_5 & 0,772 & 0.188 & Valid \\
\hline
\end{tabular}

Berdasarkan tabel diatas dari setiap butir pertanyaan yang diberikan reponden dinyatakan valid, dapat dikatakan valid apabila nilai $r_{\text {hitung }}$ lebih besar dari nilai $r_{\text {tabel}}$.

2. Uji Reliabilitas

\begin{tabular}{llll}
\hline Variabel & $\begin{array}{l}\text { Cronbach's } \\
\text { Alpha }\end{array}$ & $\begin{array}{l}\text { Nilai } \\
\text { Kritis }\end{array}$ & Keterangan \\
\hline Turnover Karyawan & 0,724 & 0,06 & Reliabel \\
Gaya Kepemimpinan & 0,805 & 0,06 & Reliabel \\
Lingkungan Kerja & 0,760 & 0,06 & Reliabel \\
Konflik & 0,848 & 0,06 & Reliabel \\
\hline
\end{tabular}

Berdasarkan tabel diatas seluruh variabel dinyatakan reliabel karena nilai cronbach's alpha lebih dari 0,06.

b) Uji Asumsi Klasik

1) Uji Normalitas 


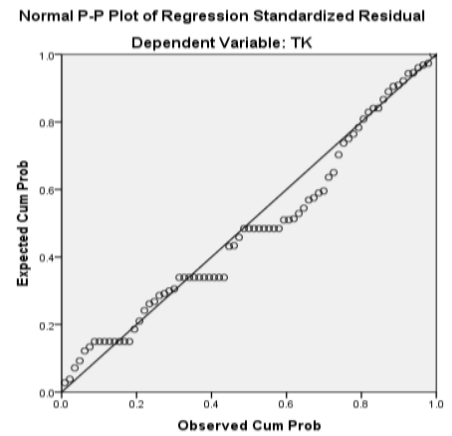

Berdasarkan gambar grafik diatas menunjukkan semua data membentuk pola dan mendekati garis diagonal. Maka dari itu dalam penelitian ini data terdistribusi normal.

2) Uji Multikolonieritas

\begin{tabular}{llll}
\hline Model & \multicolumn{2}{l}{ Collinearity Statistic } & Keputusan \\
\cline { 2 - 3 } & Tolerance & VIF & \\
\hline (Constanta) & & & \\
Gaya Kepemimpian & 0,345 & 2,899 & Bebas Multikolonieritas \\
Lingkungan Kerja & 0,367 & 2,726 & Bebas Multikolonieritas \\
Konflik & 0,748 & 1,337 & Bebas Multikolonieritas \\
\hline
\end{tabular}

Berdasarkan tabel diatas semua variabel independen masing-masing memiliki nilai tolerance kurang dari 10 dan nilai VIF lebih dari 10. Maka uji dalam penelitian ini bebas dari multikolonieritas.

3) Uji Heteroskedastisitas

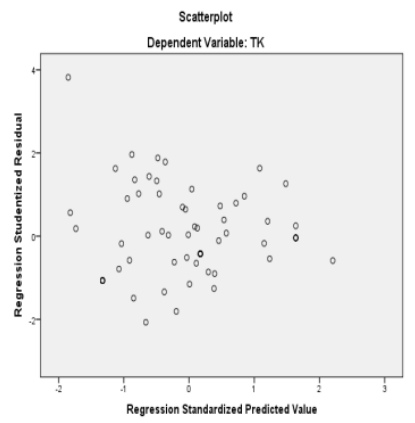

Berdasarkan gambar diatas menunjukkan seluruh titik menyebar secara acak di bawah diatas angka 0 , tidak membentuk suatu pola tertentu. Maka dalam penelitian ini tidak terjadi heteroskedastisitas.

c) Uji Hipotesis

a. Uji Regresi Linier Berganda

Memiliki persamaan regresi sebagai berikut : 
$\mathrm{Y}=10,972-0,302 \mathrm{GK}+0,286 \mathrm{LK}+0,759 \mathrm{KK}$

i. $\alpha=10,972$ menunjukkan apabila variabel terikat gaya kepemimpinan $\left(\mathrm{X}_{1}\right)$, lingkungan kerja $\left(\mathrm{X}_{2}\right)$, dan konflik $\left(\mathrm{X}_{3}\right)$ sama dengan nol atau konstanta. Maka turnover memiliki nilai sebesar 10,972.

ii. $\quad \beta_{1}=-0,302$ variabel gaya kepemimpinan memiliki nilai negatif, dapat disimpulkan apabila gaya kepemimpinan ditingkatkan maka tingkat turnover akan menurun dan akan mempengaruhi variabel yang lain.

iii. $\beta_{2}=0,286$ apabila variabel lingkungan kerja meningkat maka tingkat turnover mengalami penurunan, sedangkan variabel gaya kepemimpinan dan konflik tidak mengalami perubahan.

iv. $\beta_{3}=0,759$ variabel konflik memiliki nilai positif artinya apabila konflik meningkat maka tingkat turnover akan semakin tinggi, maka variabel dependen gaya kepemimpinan, dan lingkungan kerja akan mempengaruhi.

b. Uji F

Hasil uji simultan dengan menggunakan aplikasi SPSS 21 didapat nilai $\mathrm{F}_{\text {hitung }}>\mathrm{F}_{\text {tabel }}$ sebesar $(19,907>2,73)$ dengan memiliki nilai signifikan sebesar $(0,000<0,05)$. Sehingga Ho titolak artinya variabel terikat Gaya Kepemimpinan $\left(\mathrm{X}_{1}\right)$, Lingkungan Kerja $\left(\mathrm{X}_{2}\right)$, dan Konflik $\left(\mathrm{X}_{3}\right)$ berpengaruh secara simultan dan signifikan terhadap variabel terikat Turnover karyawan bagian sewing.

c. Uji t

i. Variabel dependen gaya kepemimpinan mempunyai nilai $t_{\text {hitung }}$ dan $t_{\text {tabel }}$ sebesar ($1,901<1,666)$. Artinya Ho diterima secara parsial maka dapat diartikan variabel dependen gaya kepemimpinan tidak berpengaruh terhadap independen turnover karyawan bagian sewing.

ii. Variabel dependen gaya kepemimpinan mempunyai nilai $t_{\text {hitung }}$ dan $t_{\text {tabel }}$ sebesar ($1,901<1,666)$. Artinya Ho diterima secara parsial, maka dapat diartika variabel dependen gaya kepemimpinan tidak berpengaruh terhadap variabel independen turnover karyawan bagian sewing.

iii. Variabel terikat lingkungan kerja mempunyai nilai $t_{\text {hitung }} \quad(2,045>1,666)$. Artinya Ho ditolak secara parsial, maka variabel lingkungan kerja memiliki pengaruh terhapad turnover karyawan bagian sewing.

iv. Variabel konflik memiliki nilai $t_{\text {hitung }}$ sebesar $(6,514>1,666)$. Artinya Ho ditolak secara parsial variabel konflik berpengaruh terhadap turnover karyawan bagian sewing. 
d. Uji Koefisien Determinan $\left(\mathrm{R}^{2}\right)$

Nilai koefisian determinan $\left(\mathrm{R}^{2}\right)$ sebesar 0,434 maka variabel dependen gaya kepemimpinan, lingkungan kerja, dan konflik dapat menjelaskan variasi variabel turnover karyawan sebesar 43,4\%.

\section{Pembahasan}

Hasil hipotesis uji $\mathrm{F}$ (simultan) dapat dilihat nilai $\mathrm{F}_{\text {hitung }}>\mathrm{F}_{\text {tabel }}$ sebesar $(19,907>2,75)$ dan nilai signifikan $(0,000<0,05)$ sehingga Ho ditolak, maka variabel Gaya Kepemimpinan $\left(\mathrm{X}_{1}\right)$, Lingkungan Kerja $\left(\mathrm{X}_{2}\right)$, dan Konflik $\left(\mathrm{X}_{3}\right)$ berpengaruh signifikan terhadap Turnover $(\mathrm{Y})$ karyawan bagia sewing PT. Solo Kawistara Garmindo.

Berdasarkan hasil hipotesis uji $t$ dapat dilihat bahwa $t_{\text {hitung }}(-1,901)<t_{\text {tabel }}(1,666)$ sehingga Ho diterima. dapat diartikan variabel independen Gaya Kepemimpinan $\left(\mathrm{X}_{1}\right)$ tidak berpengaruh terhadap Turnover (Y) karyawan bagian sewing PT. Solo Kawistara Garmindo. penelitian ini didukung dengan penelitian yang pernah dilakukan oleh Jefri Anderson (2017) mengatakan kepemimpinan berpengaruh negatif terhadap turnover intention.

Berdasarkan hasil hipotesis uji $t$ dapat dilihat nilai $t_{\text {hitung }}(2,045)>t_{\text {tabel }}(1,666)$ sehingga Ho diterima,. maka disimpulkan variabel independen Lingkugan Kerja (X2) berpengaruh terhadap variabel dependen Turnover pegawai (Y) bagian sewing PT. Solo Kawistara Garmindo. Hasil penelitian ini di dukung oleh Nur Riqoh Fuaidah (2018) menyatakan variabel lingkungan kerja berpengaruh terhadap turnover karyawan.,

Berdasarkan hasil hipotesis uji t dapat diketahui nilai thitung $(6,514)>$ ttabel $(1,666)$ sehingga Ho diterima, maka variabel indepenen Konflik (X3) berpengaruh terhadap variabel dependen Turnover pegawai (Y) bagian sewing PT. Solo Kawistara Garmindo. Penelitian ini di dukung oleh Ni Luh Neva Krestya (2015), menyatakan variabel konflik kerja memiliki pengaruh positif dan signifikan terhadap turnover karyawan.

\section{KESIMPULAN}

a) Hipotesis pertama mengatakan bahwa variabel independen Gaya Kepemimpinan (X1), Lingkungan Kerja (X2), dan Konflik (X3) secara simultan berpengaruh dan signifikan terhadap variabel dependen Turnover (Y)

b) Hipotesis kedua menyatakan variabel Gaya Kepmimpinan $\left(\mathrm{X}_{1}\right)$ secara parsial tidak berpengaruh terhadap turnover (Y).

c) Hipotesis ketiga mengatakan variabel independen Lingkungan Kerja $\left(\mathrm{X}_{2}\right)$ secara parsial terdapat pengaruh terhadap variabel dependen turnover $(\mathrm{Y})$.

d) Hipotesis kempat variabel independen Konflik $\left(\mathrm{X}_{3}\right)$ secara parsial pengaruh terhadap variabel dependen turnover $(\mathrm{Y})$.

\section{Saran}

a. Pemimpin untuk meningkatkan kualitas diri dari kepemimpina yang ada sekarang karena variabel gaya kepemimpinan yang diteliti tidak ada pengaruh maka diharapkan masa mendatang apabila terjadi pergantian pemimpin maka tingkat kualitas ditingkatkan dalam upaya menurunkan tingkat turnover.

b. Dari sudut pandang lingkungan non fisik pihak perusahaan memberikan reward bagi karyawan dengan kinerja yang baik, dengan adanya penghargaan bagi pegawai atas kerja keras untuk 
perusahaan maka dapat menjadi pemicu kepuasan kerja karyawan dan dapat menurunkan tingkat turnover.

c. Tingkat turnover dapat teratasi apabila pihak perusahaan memberi kompensasi yang sesuai dengan pekerjaan, tanggung jawab dan kemampuan yang dimiliki pegawai. Maka dengan diberikan kompensasi yang setimpal pegawai akan merasa puas dan tidak berfikir untuk meninggalka pekerjaan meskipun perusahaan lain memberikan kompensasi yang lebih besar.

d. Untuk penelitian berikutnya diharapkan untuk dapat mengembangkan penelitian dengan menggunakan variabel lain.

\section{DAFTAR PUSTAKA}

Anderson, J. (2017). Pengaruh Kepemimpinan Dan Lingkungan Kerja Non Fisik Terhadap Kepuasa Kerja Perawat Melalui Turnover Intention Perawat Pada Rumah Sakit Syafira Pekanbaru. JOM Fekom Vol. 4 No. 1 Februari 2017.

Fuaidah. N.F. (2018). Pengaruh Kompensasi Karyawan Dan Lingkungan Kerja Karyawan Terhadap Turnover Intention (Studi pada Karyawan Auto 2000 Malang-Sutoyo). Jurnal Administrasi Bisnis (JAB) Vol. 60 No.2 Juli 2018.

Hasibuan, Melayu, 2011. Manajemen Dasar, Pengertian dan Masalah. Jakarta: PT. Bumi Aksara

Issa, D.A.R., Ahmad, F dan Gelaidan, H.M. (2013). Job Satisfaction and Turnover Intention Based on Sales Person Standpoint. Middle East Journal of Scientific Research, Vol. 14, No. 4, 523 531.

Kartono, Kartini. (2008). Pemimpin dan Kepemimpinan. Jakarta: Raja Grafindo Persada.

Khotimah, R. D., Djumali, D., \& Pawenang, S. (2019). Analisa Kepuasan Kerja, Komitmen Organisasi dan Lingkungan Kerja terhadap Turnover Intention Karyawan (Studi Kasus pada Karyawan Bagian Sewing PT dan Liris). Jurnal Ilmiah Edunomika, 3(02).

Nanda, N.L.N.K. (2015). Pengaruh Konflik Kerja-Keluarga Dan Kepuasan Kerja Terhadap Tingkat Tunrover Intention Karyawan Pada Restoran Pizza Hut Mall Bali Galeria. E-jurnal Manajemen Unud Vol. 4 No. 9,: 2461-2477.

Sedarmayanti, 2013. Sumber Daya Manusia dan Produktivitas Kerja. Mandar Maju: Bandung.

Wirawan, 2010. Konflik dan Manajemen Konflik: Teori, aplikasi, dan penelitian, Jakarta: Salemba Humanika. 